\title{
Proportions of demersal fish exposed to sublethal hypoxia revealed by otolith chemistry
}

\author{
Matthew E. Altenritter ${ }^{1,2, *}$, Alfonso Cohuo ${ }^{1}$, Benjamin D. Walther ${ }^{1}$ \\ ${ }^{1}$ Texas A\&M University-Corpus Christi, 6300 Ocean Drive Unit 5858, Corpus Christi, TX 78412, USA \\ ${ }^{2}$ Present address: University of Illinois at Urbana-Champaign, Illinois Natural History Survey, 704 N. Schrader, Havana, \\ IL 62644, USA
}

\begin{abstract}
Fishes exposed to hypoxia may experience sublethal effects that impair growth, reproductive fitness, and condition, with potential consequences for population sustainability. Characterizing sublethal effects of hypoxia exposure requires the ability to differentiate between exposed, and non-exposed individuals. Moreover, because sublethal effects may manifest well after exposure to hypoxia has ceased, long-term markers that facilitate retrospective identification of exposure are necessary. We used sagittal otoliths from 337 Atlantic croaker Micropogonias undulatus sampled at multiple stations in the northern Gulf of Mexico to characterize exposure to hypoxia during the first year of life. Otolith elemental profiles of $\mathrm{Ba}: \mathrm{Ca}$ and $\mathrm{Mn}$ :Ca revealed 4 primary clusters of fish associated with residence in normoxic, hypoxic, and estuarine habitats. Croaker exposed to hypoxia in the first year of life constituted $34 \%$ of all individuals sampled in fall of 2014, and this pattern was consistent across the sampling region. Young-of-year croaker exposed to hypoxia were smaller in length and mass but had similar mean relative condition factors to croaker of the same year class experiencing normoxic conditions. These results indicate that in some years, one-third of the young-of-year croaker in the northern Gulf of Mexico experience hypoxic conditions and survive. The potential for sublethal effects of hypoxia on growth may be important for future efforts to forecast population sustainability under chronic seasonal hypoxia in the region.
\end{abstract}

KEY WORDS: Hypoxia · Otolith chemistry · Gulf of Mexico · Atlantic croaker

\section{INTRODUCTION}

Depletion of dissolved oxygen (DO) in marine and freshwater systems to levels at or below $2.0 \mathrm{mg} \mathrm{l}^{-1}$ (i.e. hypoxia; Diaz \& Rosenberg 2008) is geographically widespread and can have both lethal and sublethal consequences for demersal fishes (Breitburg 2002). Bottom water hypoxia is primarily facilitated by excessive nutrient inputs and the seasonal establishment of thermohaline stratification of the water column (Rabalais et al. 2010). Excessive phytoplankton production due to seasonal nutrient enrichment results in large additions of organic matter to the benthos, which stimulates benthic respiration (Tur-

${ }^{*}$ Corresponding author: mea5@illinois.edu ner \& Rabalais 1994). Because the benthos is separated from surface aeration by stratification, bottom water oxygen is depleted and so-called 'dead zones' can form. Such eutrophication-driven 'dead zones' have been documented in 480 coastal marine systems across the globe (Rabalais et al. 2014), while large hypoxic regions also form seasonally in portions of the Laurentian (Scavia et al. 2014, Hamidi et al. 2015) and African (Hecky et al. 1994) Great Lakes. When dissolved oxygen concentrations change rapidly, and faunal avoidance is impeded either physically or behaviorally, hypoxia exposure may be lethal to fishes (Breitburg et al. 2009). However, it is likely that exposure to hypoxia also results in sublethal

(C) The authors 2018. Open Access under Creative Commons by Attribution Licence. Use, distribution and reproduction are unrestricted. Authors and original publication must be credited. 
effects that manifest as growth impairments (Chabot \& Dutil 1999), reproductive impairments (Wu et al. 2003), or reduced condition factors (Mohan et al. 2014). Therefore, whether or not sublethal consequences at the individual level translate to effects at higher levels of ecological organization requires the identification of individuals exposed to hypoxia.

Hypoxia in the northern Gulf of Mexico is a chronic, seasonal phenomenon that has important consequences for fisheries and ecosystem dynamics. The seasonal development of hypoxia in this region is largely a function of excess nutrient inputs from the Mississippi and Atchafalaya River basins and thermohaline stratification (Rabalais et al. 2002). Generally forming between March and May and lasting through August, the extent of seasonal bottom water hypoxia in this system averaged $15900 \mathrm{~km}^{2}$ between 1993 and 2007 and constitutes one of the largest hypoxic zones in the world (Rabalais et al. 2007). The variable spatial extent of hypoxia in the Gulf of Mexico may also have implications for the likelihood of exposure, with some evidence of variability in exposure based on geographic location in and around the hypoxic zone (Mohan \& Walther 2016). We used the Atlantic croaker Micropogonias undulatus (hereafter referred to as croaker) as the study species to characterize the extent of hypoxia exposure in a demersal fish from the northern Gulf of Mexico hypoxic zone. The croaker is a ubiquitous, estuarine-dependent fish species that displays relatively high tolerance to hypoxia (Wannamaker \& Rice 2000, Bell \& Eggleston 2005). In the northern Gulf of Mexico, late juvenile croaker are known to aggregate around the margins of hypoxic zones (Craig \& Crowder 2005). Croaker aged young-of-year (YOY) to 1 yr old may also continue to feed on benthic organisms in spite of hypoxia exposure (Mohan \& Walther 2016). However, despite the relative tolerance and trophic resilience croaker display in the face of hypoxia, YOY croaker suffered growth impairments and subsequent declines in condition when exposed to 4 and $10 \mathrm{wk}$ of constant hypoxia (1.7 $\left.\mathrm{mg} \mathrm{l}^{-1} \mathrm{DO}\right)$ in laboratory experiments (Mohan et al. 2014). Moreover, a suite of severe reproductive impairments due to hypoxia have been observed including decreased production and viability of gametes in adult YOY males and females (Thomas \& Rahman 2009, 2010, Thomas et al. 2015) and ovarian masculinization in adult YOY females (Thomas \& Rahman 2012).

Severe reproductive impairments stemming from direct hypoxia exposure may subsequently result in declining croaker population abundance in the northern Gulf of Mexico (Rose et al. 2009). Modelling estimates of century-scale population responses to hypoxia exposure suggests that the magnitude of population decline depends strongly on the proportion of juvenile croaker exposed to hypoxia in the first year of life (Rose et al. 2009). Specifically, if only $10 \%$ of juvenile croaker experience hypoxia in their first year, then population abundance declines after $100 \mathrm{yr}$ are minimal, whereas population abundances would decline by $52 \%$ if half of all juvenile croaker experience hypoxia in the first year of life (Rose et al. 2009). Such declines in abundance would negatively impact fisheries for this species that annually account for 47-64 metric tons of commercial harvest (2000-2013) and 373-467 metric tons of recreational harvest (2000-2014) in the Gulf of Mexico (NMFS $2015 \mathrm{a}, \mathrm{b})$. To date, these modelling estimates of croaker population response to hypoxia have used arbitrary estimates of proportional hypoxia exposure, and little data about the true exposure proportions exist. Thus, quantifying the actual proportion of croaker exposed to hypoxia in the northern Gulf of Mexico is critical to understanding the potential consequences for croaker abundance with implications for fishery sustainability.

Molecular markers have previously been used to identify hypoxia exposure in adult YOY croaker in both laboratory and natural field settings (Thomas \& Rahman 2009, 2012). However, molecular indicators are only diagnostic within $24 \mathrm{~h}$ of hypoxia exposure (Rahman \& Thomas 2007), with limited applicability to examinations of lifetime exposure patterns. An alternative method for reconstructing environmental histories over the entire life of a fish is geochemical proxies in otoliths or 'ear stones' (Campana 1999, Campana \& Thorrold 2001). This approach has been used extensively to describe differential habitat use based on salinity differences. For example, concentrations of barium in ratio to calcium (Ba:Ca) in water typically vary inversely with salinity, providing a basis for reconstructing movements across salinity gradients (Elsdon \& Gillanders 2005, Walther \& Nims 2015). As croaker exit nursery estuaries for marine environments where they will eventually spawn (White \& Chittenden 1977), declining Ba:Ca with increasing salinity serves as a marker for inhabitance of marine waters where some individuals may eventually encounter hypoxic conditions. The ratio of otolith manganese to calcium (Mn:Ca) as a geochemical proxy for dissolved oxygen concentrations was previously suggested by Thorrold \& Shuttleworth (2000) and more recently applied to describe hypoxia exposure patterns in fishes (Limburg et al. 2011, 2015, Mohan \& Walther 
2016). Under hypoxic conditions, particulate manganese oxides in aquatic sediments are reduced to dissolved $\mathrm{Mn}^{2+}$ that can flux out of the sediments (Laslett 1995), resulting in elevated manganese concentrations in bottom waters (Lewis \& Luther 2000, Statham et al. 2005). Importantly, Mohan et al. (2014) observed that hypoxic conditions $\left(1.7 \mathrm{mg} \mathrm{l}^{-1}\right.$ DO) in the absence of water chemistry differences did not result in elevated otolith $\mathrm{Mn}$ :Ca in YOY croaker, indicating minimal physiological alteration of elemental tracers due to oxic stress alone. Elevated Mn:Ca concentrations in sagittal otoliths of demersal fishes exposed to hypoxia have been documented across multiple systems from Atlantic cod Gadus morhua in the Baltic Sea (Limburg et al. 2011, 2015), yellow perch Perca flavescens in Lake Erie (Limburg et al. 2015), and Atlantic croaker from the northern Gulf of Mexico (Mohan \& Walther 2016). In the northern Gulf of Mexico, the use of otolith proxies to define the proportion of fish exposed to hypoxia has yet to be established, and the subsequent sublethal effects of hypoxia exposure on growth and condition of wild fish have yet to be characterized.

The overall objective of this work was to characterize the diversity of exposures to normoxic, hypoxic, and estuarine environments in croaker and identify potential sublethal effects of exposure to hypoxia on growth and condition. Specifically, we measured chemical proxies for salinity (Ba:Ca) and dissolved oxygen concentrations (Mn:Ca) in sagittal otoliths from croaker in order to (1) quantify the proportion of sampled croaker exposed to hypoxic conditions and (2) examine potential sublethal effects of hypoxia exposure on growth and relative condition factors of croaker.

\section{MATERIALS AND METHODS}

\section{Fish collection and otolith preparation}

Croaker Micropogonias undulatus from the northern Gulf of Mexico were collected during Leg II (23 October to 5 November) of the 2014 NOAA Southeast Monitoring and Assessment Program (SEAMAP) fall ground fish survey aboard the RV 'Oregon II'. Sampling occurred in autumn to allow for detection of potential hypoxia exposure during the preceding summer, when hypoxia extent was greatest in the region. Sampling stations were chosen based on a stratified random design, which allocated stations according to the surface area of Gulf coast shrimp statistical zones (GSMFC 2017). At 22 stations (Fig. 1), croaker were sampled using a benthic trawl (12.8 m long with $41 \mathrm{~mm}$ stretch mesh; SEDAR 2017) deployed for $30 \mathrm{~min}$. Profiles of water temperature $\left({ }^{\circ} \mathrm{C}\right)$, depth $(\mathrm{m})$, dissolved oxygen $\left(\mathrm{mg} \mathrm{l}^{-1}\right)$, and salinity were measured at each station (see Table S1 in the Supplement at www.int-res.com/articles/suppl/ m589p193_supp.pdf). Sampled croaker were stored frozen $\left(-20^{\circ} \mathrm{C}\right)$ until processing where between 4 and

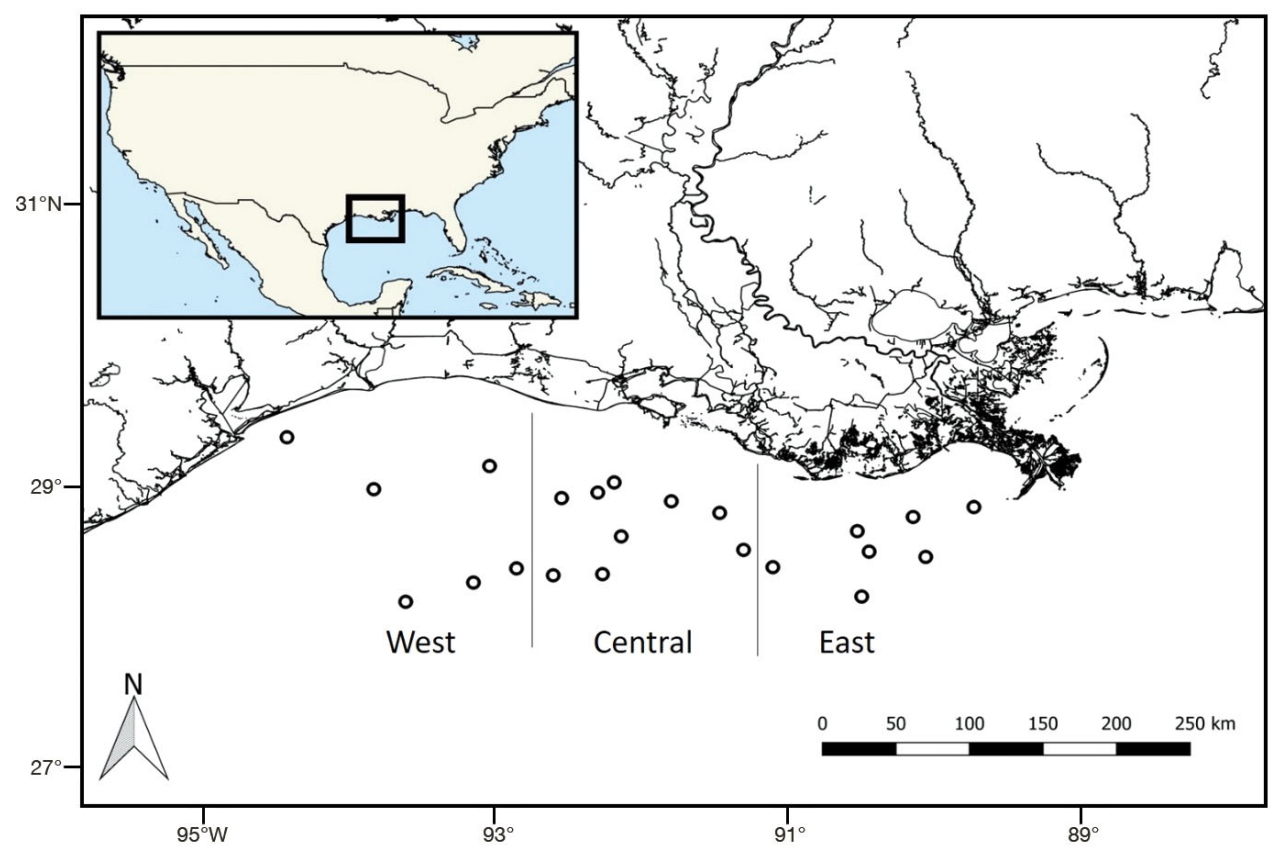

Fig. 1. NOAA SEAMAP sampling stations (open circles) where Atlantic croaker were collected in October and November 2014. Stations spanned the typical summertime hypoxic zone in the northern Gulf of Mexico. Vertical lines demarcate western, central, and eastern regions used for regional comparison of exposure type representation 
23 croaker per station were used in subsequent analyses (Table S1).

In the lab, croaker were thawed, measured for total length to the nearest millimeter, lightly patted dry with a paper towel, and weighed to the nearest $0.1 \mathrm{~g}$. Both sagittal otoliths were removed from each fish, rinsed with deionized water to remove adhering tissue, and allowed to air dry in plastic vials. Once dry, the left sagittal otolith was embedded sulcus-side down in clear 2-part epoxy (Epoxicure; Buehler). Embedded otoliths were thick-sectioned (1-2 mm) along the transverse plane using an Isomet lowspeed saw (Buehler) and affixed to petrographic slides with a small amount of thermoplastic glue (Crystalbond 509). Slide-affixed otolith sections were then sequentially polished on $30 \mu \mathrm{m}$ and $3 \mu \mathrm{m}$ lapping films to approximate the position of the otolith core. Each otolith section was independently aged by 2 readers. All ageing was conducted blind without knowledge of sampling station or attributes of the fish. If age disagreement occurred between the 2 readers, the readers attempted to reach an age consensus together. If agreement could still not be reached, the otolith was discarded. While otolith ageing was not validated in this study, it has been validated for this species in the northern Gulf of Mexico (Barger 1985), and thus, 1 pair of opaque and translucent bands was considered representative of 1 annulus. Croaker aged YOY were presumed hatched in October to November 2013. Only croaker aged YOY, Age-1 and Age-2 were retained for further analyses. Older fish were not included given the low probability of encountering older individuals in trawl samples (Barger 1985). After ageing, otolith sections were transferred to another petrographic slide (12 otolith sections per slide) to minimize the need to exchange sample slides during subsequent otolith chemical analyses, rinsed with deionized water, and allowed to air-dry under a class 100 laminar flow hood.

\section{Otolith chemical analyses}

Otolith chemical analyses on the same sections used for aging were conducted at the University of Texas at Austin Jackson School of Geosciences. Elements were measured using an Agilent 7500ce ICPQ-MS coupled to a New Wave UP 193-FX laser. Laser transects began at the otolith core and ended at the otolith edge along the longest dorso-ventral axis. Prior to data collection, transects were pre-ablated (50 $\mu \mathrm{m}$ spot, $50 \mu \mathrm{m} \mathrm{s}^{-1}$ ) to remove surface contamination. The counts of ${ }^{44} \mathrm{Ca},{ }^{55} \mathrm{Mn}$, and ${ }^{138} \mathrm{Ba}$ were acquired with a mean laser power over 17 analytical days of $5.73 \mathrm{~J} \mathrm{~cm}^{-2}\left(\mathrm{SD}=1.70 \mathrm{~J} \mathrm{~cm}^{-2}\right)$. Transects were ablated using a $25 \mu \mathrm{m}$ spot diameter and a scan rate of $5 \mu \mathrm{m} \mathrm{s}^{-1}$. Standard reference materials included a National Institutes of Standards and Technology glass (NIST-612) and U.S. Geological Survey MACS3 calcium carbonate pressed pellet. Standards were run in triplicate before and after every hour of otolith analyses (i.e. every 5 to 6 otolith transects) to correct for analytical drift and assess precision and to convert raw intensities to molar concentrations, respectively. Raw intensity data were reduced and converted to molar ratios relative to $\mathrm{Ca}$ using the software package Iolite. Calcium concentration in aragonite was assumed to be $37.69 \mathrm{wt} \%$ and used as an internal standard. Mean relative standard deviations (RSD) for NIST 612 ( $\mathrm{n}=322$ ) over $17 \mathrm{~d}$ as a metric of analytical precision for Mn:Ca and Ba:Ca were $3.63 \%$ and $3.19 \%$, respectively.

The otolith chemical data collected along the analytical transect were then truncated such that only data falling within the first year of life were retained for comparison. In YOY croaker, data from the entire core to edge transect were used. In Age-1 and Age-2 individuals, the imaging software package Zen Pro (Zeiss) was used to measure the transect distance between the core and end of Year 1, or where the analytical transect encountered the first distinct opaque zone in the otolith. While some evidence for protracted spawning of croaker in the northern Gulf of Mexico exists (Hernandez et al. 2010, Kupchik \& Shaw 2016), it appears that most larvae hatch in the months of October and November (Hernandez et al. 2010, Thomas et al. 2015). Marginal increment analysis of croaker otoliths conducted by Barger (1985) demonstrated that few (i.e. $<5 \%$ ) of the individuals display opaque otolith margins prior to the month of December. Thus, we assumed any otolith chemical data collected prior to the deposition of the first opaque zone in 1 and 2 yr old fish would approximate the first year of life in those individuals. Otolith chemical data from the first year of life for all individuals across the 3 age classes (mean \pm SD: $1064 \pm 132$ transect points) were smoothed with a 5 point moving median and then a 5 point moving mean to remove high frequency points and smooth the data, respectively (Sinclair et al. 1998).

\section{Cluster analysis and exposure diversity}

To group individual fish based on chemical profiles in the otolith, we applied an indexing system devel- 
oped by Mohan \& Walther (2016) that compared otolith element:calcium concentrations to a set of threshold values for both $\mathrm{Ba}: \mathrm{Ca}$ and $\mathrm{Mn}: \mathrm{Ca}$. To develop these thresholds, Mohan et al. (2014) estimated mean partition coefficients ( $\mathrm{D}=$ [element: $\left.\mathrm{Ca}_{\text {otolith }}\right]$ / [element: $\mathrm{Ca}_{\text {water }}$ ]) for $\mathrm{Ba}: \mathrm{Ca}$ and $\mathrm{Mn}: \mathrm{Ca}$ using laboratory reared croaker held under constant (mean $\pm \mathrm{SD}$ ) dissolved oxygen $\left(2.1 \pm 0.3\right.$ and $\left.6.3 \pm 0.3 \mathrm{mg} \mathrm{l}^{-1}\right)$ and salinity $(36.5 \pm 2.8$ and $37.7 \pm 2.5)$ conditions. The mean partition coefficient for each element:calcium ratio was then multiplied by in-field water chemistry measurements representative of estuarine, normoxic, and hypoxic environments in the northern Gulf of Mexico.

The estuarine index value for an individual was determined solely based on the ratios of $\mathrm{Ba}$ :Ca across each transect. For each Ba:Ca data point within a transect, a threshold value of 0 was assigned if the otolith Ba:Ca was $<20 \mu \mathrm{mol} \mathrm{mol}^{-1}$, with this threshold being the established estuarine threshold based on water chemistry sampling in the region (Mohan \& Walther 2016) and lab-validated partition coefficients (Mohan et al. 2014). Data points were assigned values of 1,2 , or 3 if they exceeded the estuarine threshold by 1-, 2-, or 3-fold, respectively. Values for successive data points were then summed across the transect from the core to either the edge (for YOY fish), or the first annulus, to obtain a total index of estuarine habitat use during the first year of life (Fig. 2).

The hypoxia index was calculated for each individual using a similar method, but was based on the $\mathrm{Mn}: \mathrm{Ca}$ ratios for each data point in the transect portion representing the first year of life (up to the otolith edge in YOY and up to the first annulus in older fish). Values of 0 were assigned for otolith $\mathrm{Mn}$ :Ca ratios that were $<100 \mu \mathrm{mol} \mathrm{mol}^{-1}$ based on the developed hypoxia indicator thresholds for the region (Mohan \& Walther 2016) and assigned a 1, 2, or 3 for values exceeding that threshold by 1-, 2-, or 3-fold, respectively. The hypoxia index was modified in one additional way. If a given data point along a transect had a corresponding $\mathrm{Ba}$ :Ca ratio above the estuarine threshold, indicating estuarine residence, the hypoxia index value was automatically set to 0 for that data point regardless of the observed $\mathrm{Mn}$ :Ca ratio. This was done in order to exclude potential estuarine hypoxia from being included in the developed hypoxia index and therefore to ensure that the hypoxia index only reflected hypoxia experience at high salinities that would be experienced during residence on the continental shelf.

Finally, to assess the potential extent of estuarine hypoxia that was not included in the hypoxia index it- self, we developed a separate simultaneity index based on the original $\mathrm{Ba}: \mathrm{Ca}$ and $\mathrm{Mn}$ :Ca ratios within each transect for the first year of life. If a given data point had Ba:Ca and Mn:Ca ratios that both exceeded their respective thresholds simultaneously, that data point was assigned a value of 1 . The data point was assigned a value of 0 if either $\mathrm{Ba}: \mathrm{Ca}$ or $\mathrm{Mn}$ :Ca was below their respective thresholds. Simultaneity index values were then summed for the first year of life as above. This index therefore allowed us to determine the extent of estuarine hypoxia experience that was not included in the hypoxia index that solely indicated high salinity hypoxia. Each fish thus received 3 overall index values indicating estuarine, hypoxia, and simultaneous threshold exceedance.

The 3 index values of estuarine, hypoxia, and simultaneity for each individual were then used in a hierarchical cluster analysis to identify groups based on exposure history during the first year of life. Ward's method was applied such that clusters were composed of individuals that were maximally similar based on minimizing the variance within each cluster (Ward 1963, Mohan \& Walther 2016). To examine if the number of points in the truncated transects could be biasing the exposure index values, we applied a 1-way ANOVA on square root transformed transect point counts (to meet the assumptions of normality and homoscedasticity) to test for differences in the mean number of transect points among exposure types. A chi-squared goodness of fit test was used to test for differences in cluster representation between YOY and Age-1 fish. Two-year-old individuals were not included because of small sample sizes (e.g. $\mathrm{n}=$ 2 ) in some clusters. All significance testing was conducted at $\alpha=0.05$.

\section{Geographic comparisons}

The proportional exposure by geographic region was examined to validate a roughly equivalent likelihood of sampling all exposure types regardless of sampling station location. Three regions - west, central, and east-were arbitrarily delineated by partitioning the maximum distance between the furthest east and west stations into 3 spatially equivalent zones. These delineations respectively included 6, 9, and 7 stations and 88, 139, and 110 individuals (Fig. 1). The proportion of fish from all 3 age classes falling into pooled exposure types (e.g. estuarine, hypoxic, normoxic) within a region was compared among regions using a chi-squared goodness of fit test. 



Fig. 2. Example Mn:Ca and Ba:Ca profiles from Atlantic croaker denoted as experiencing hypoxic and estuarine conditions. Dashed lines delimit the respective otolith element thresholds and $2 \times$ and $3 \times$ the thresholds. Index values were summed across the first year of life to develop hypoxia and estuarine indices. Distance measures the length $(\mu \mathrm{m})$ of the otolith transect from the core to the edge 


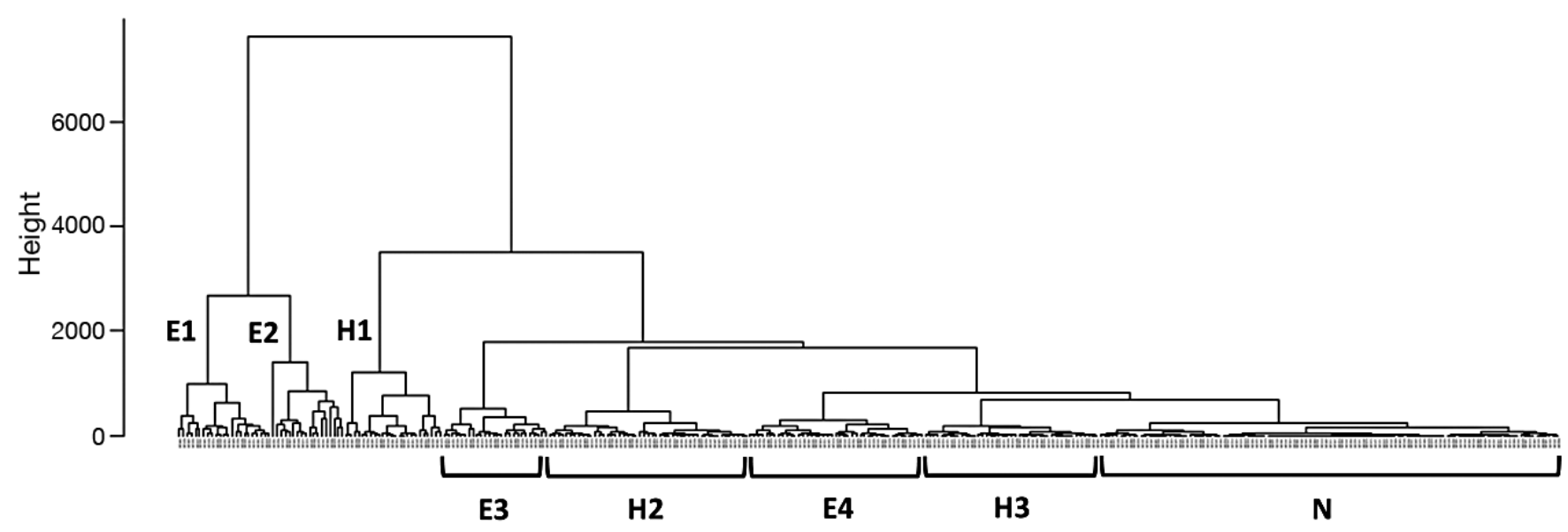

Fig. 3. Dendrogram of exposure types of Atlantic croaker based on hypoxia and estuarine indices. Four primary and 5 subclusters (falling within the largest primary cluster) were defined using Ward's method. Clusters represented one normoxic group (N), 3 hypoxic groups (H1 - H3), and 4 estuarine groups (E1 - E4)

\section{Biometric comparisons}

Comparisons of total length $(\mathrm{mm})$, wet mass $(\mathrm{g})$, and relative condition factor $\left(K_{n}\right)$ among exposure types were conducted only for YOY fish to control for possible effects of age (e.g. compensatory growth). Analyses were carried out on biometric data pooled by exposure type. Subsequent exposure types for YOY fish included normoxic $(\mathrm{n}=34)$, hypoxic $(\mathrm{n}=$ $36)$, and estuarine $(n=32)$. Total length and wet mass measurements failed to meet the parametric assumptions of normality and homoscedasticity and thus were compared among exposure types using a nonparametric Kruskal-Wallis ANOVA and Dunn's post hoc test for multiple comparisons with an adjusted pvalue based on the number of comparisons. Relative condition factor was calculated as follows:

$$
K_{\mathrm{n}}=\frac{M}{M^{\prime}} \times 100
$$

where $M$ is the observed mass of an individual $(\mathrm{g})$, and $M^{\prime}$ is the predicted length-specific mass based on the linear relationship between log transformed length and mass (Le Cren 1951). Values of $K_{\mathrm{n}}$ by exposure type passed normality (Shapiro-Wilk test) and equal variance (Bartlett's test) assumptions and were compared using a 1-way ANOVA and Holm-Sidak multiple comparisons tests with an adjusted p-value for the number of comparisons (Holm 1979, Sokal \& Rohlf 1995).

\section{RESULTS}

A total of 339 croaker from 22 NOAA SEAMAP fall groundfish stations in the northern Gulf of Mexico were collected for examination of exposure history. Readers independently agreed on ages for 326 fish (96\%) and came to consensus on a further 11 fish (99\%). Two individuals were excluded from further analyses due to age discrepancies that could not be resolved between readers, leaving 337 total fish included in chemical analyses. Croaker sample sizes by age included 102 YOY (30\%), 197 Age-1 (59\%), and 38 Age-2 (11\%) individuals. Ward's cluster analysis revealed 4 clusters based on the exposure indices (Fig. 3). These included 2 'estuarine' clusters ( $\mathrm{n}=23$ and 18), 1 'non-estuarine hypoxia' cluster ( $\mathrm{n}=$ 24), and 1 cluster comprising a mixture of exposure types ( $\mathrm{n}=272$; Fig. 4). Five sub-clusters were designated within the fourth cluster based on differences in estuarine and hypoxia index values (Fig. 4). They included 2 additional estuarine clusters ( $\mathrm{n}=26$ and 42), 2 additional non-estuarine hypoxia clusters ( $\mathrm{n}=$ 49 and 42), and 1 'non-estuarine normoxia' cluster ( $\mathrm{n}=113$ ). Overall representation by exposure type included 109 estuarine (32\%), 115 hypoxic (34\%), and 113 normoxic (34\%) individuals. The mean number of truncated transect points was not different among these exposure types $\left(F_{2,334}=0.395, \mathrm{p}=\right.$ $0.674)$. The proportional representation of each cluster between YOY and Age-1 was not different $\left(\chi^{2}=\right.$ 2.96, $\mathrm{df}=7, \mathrm{p}=0.888$; Table 1 ).

Exposure to normoxia was characterized by low values of estuarine (Ba:Ca), hypoxia (Mn:Ca), and simultaneity index values (Fig. 4). Hypoxia clusters displayed elevated hypoxia index values and low estuarine and simultaneity index values (relative to normoxic and estuarine types). The estuarine clusters displayed low hypoxia index values and a gradient of elevated estuarine index values (Fig. 4), all of which 

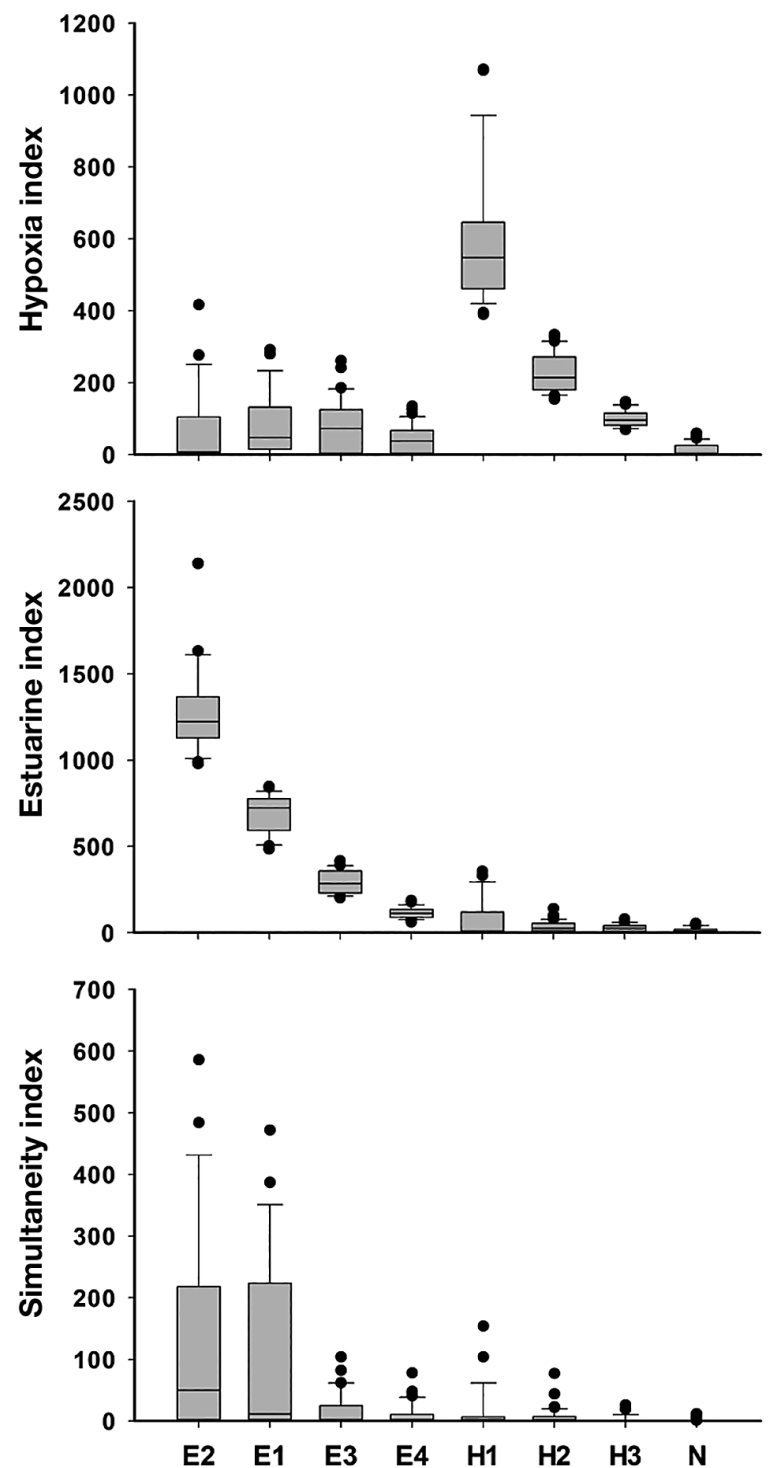

Fig. 4. Exposure index values of chemical profiles of Atlantic croaker otoliths for each of the 8 clusters (see Fig. 3 for codes) represented by hypoxia, estuarine, and simultaneity index values. The box indicates the median, 25 th and 75 th percentile. Whiskers indicate the 10th and 90th percentiles, and individual points are outliers

Table 1. Proportional cluster representation as denoted in Fig. 3 of Atlantic croaker sampled in 2014 for all 3 age classes. Exposure types include normoxia (Norm), hypoxia $(\mathrm{H} 1$ - H3), and estuarine (E1 - E4). Numbers in parentheses indicate sample sizes. $\mathrm{N}$ represents the total number of individuals falling within a given cluster

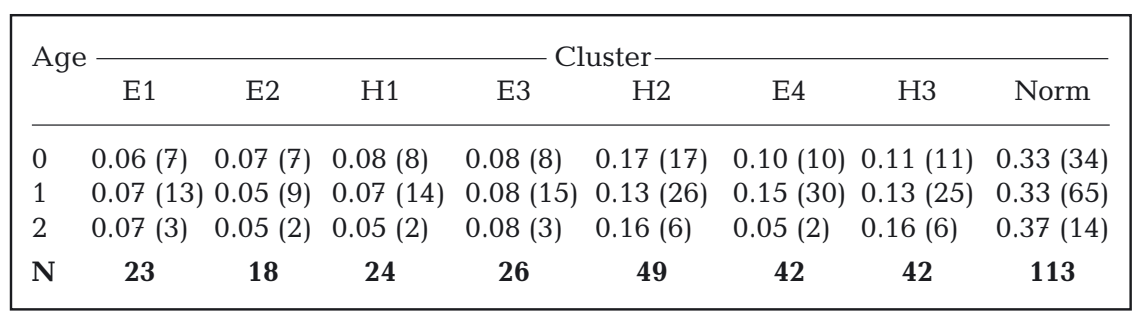

exceeded the estuarine index values for normoxic and hypoxic clusters. Simultaneity index values displayed the most variation among estuarine clusters, but did not contribute to significant differences among those clusters (Fig. 4) and were therefore not considered further. Proportional representation of pooled exposure types was not dependent on the geographic region of sampling $\left(\chi^{2}=6.35\right.$, $\mathrm{df}=4, \mathrm{p}=0.174$; Table 2$)$.

Both YOY median total length and median wet mass differed among exposure types (Kruskal-Wallis $\mathrm{p}<0.001$ for both metrics). Median total length of YOY croaker exposed to normoxia was greater than for croaker in both the hypoxia (Dunn's post hoc p < 0.001) and estuarine exposure (Dunn's post hoc p < 0.001) types; however, median total length was not different between hypoxia and estuarine types (Dunn's post hoc $\mathrm{p}=0.45$; Fig. 5). Median wet mass followed the same pattern as total length with no difference in wet mass between hypoxic and estuarine types (Dunn's post hoc p > 0.05; Fig. 5). While a marginally significant difference in mean YOY $K_{\mathrm{n}}$ among exposure types was observed (ANOVA $F_{2,99}=3.138$, $\mathrm{p}=0.048)$, no pairwise comparisons were significant (Fig. 5).

\section{DISCUSSION}

Croaker sampled from the northern Gulf of Mexico display diverse life histories associated with putative exposure to hypoxic, normoxic, or estuarine conditions. Direct exposure to various dissolved oxygen and salinity regimes elucidated using ratios of $\mathrm{Mn}: \mathrm{Ca}$ and $\mathrm{Ba}: \mathrm{Ca}$ in sagittal otoliths indicate $34 \%$ of croaker sampled in fall of 2014 previously experienced hypoxia during their first year of life. This estimate is higher than previously estimated proportions of croaker exposed to hypoxia in the northern Gulf of Mexico (17 to $21 \%$; J. Mohan pers. comm.) and is likely because the prior analysis was restricted to otolith material deposited over a shorter time period (the final 3 mo of life) and with less potential temporal overlap with the hypoxic region (Mohan \& Walther 2016) than the period of time examined in this study (i.e. the entire first year of life including 1 full hypoxic season). While a similar proportion of sampled croaker $(34 \%)$ inhabited normoxic waters during the first year of life, $32 \%$ displayed 
Table 2. Proportional representation of exposure types by sampling region (Fig. 1) and in total. Proportions include Atlantic croaker from all 3 age classes (YOY to age 2). Numbers in parentheses indicate sample sizes

\begin{tabular}{|c|c|c|c|}
\hline \multirow{2}{*}{ Region } & \multicolumn{3}{|c|}{ Exposure type } \\
\hline & Normoxia & Hypoxia & Estuarine \\
\hline West & $0.34(38)$ & 0.25 (29) & $0.19(21)$ \\
\hline Central & $0.35(40)$ & $0.42(48)$ & $0.47(51)$ \\
\hline East & $0.31(35)$ & $0.33(38)$ & $0.34(37)$ \\
\hline Total & 0.34 (113) & $0.34(115)$ & $0.32(109)$ \\
\hline
\end{tabular}
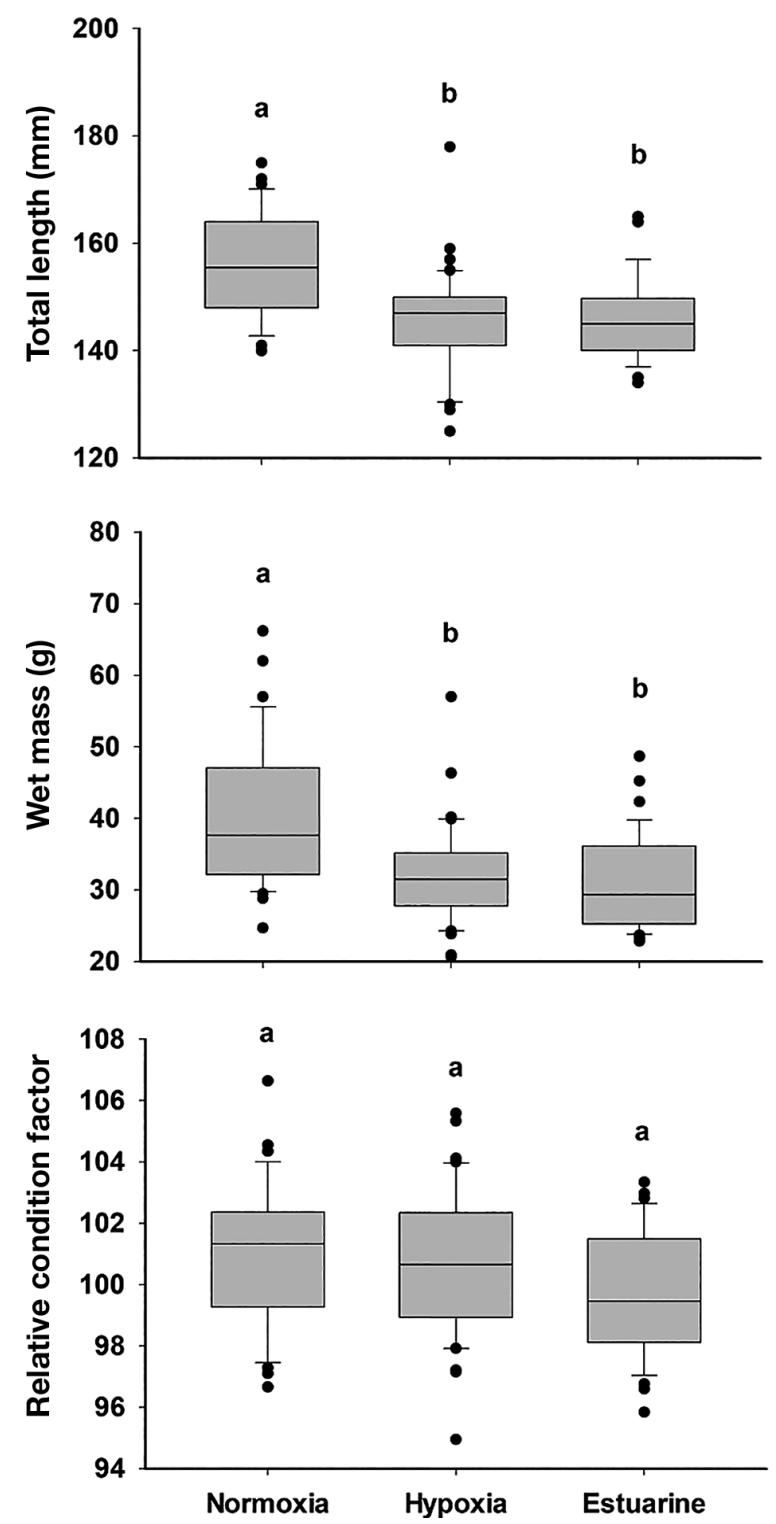

Fig. 5. Total length, wet mass, and relative condition factor for Age-0 Atlantic croaker pooled by exposure type. Box plot details as in Fig. 4. Different lowercase letters indicate significant differences in median total length, wet mass, or mean relative condition factor chemical signatures reflective of putative estuarine conditions, which is unexpected given that this species is assumed to use estuaries extensively (Haven 1957, Miglarese et al. 1982, Ross 2003, Able \& Fahay 2010). The median total length of YOY croaker was different at capture between croaker exposed to normoxia and those exposed to hypoxia, suggesting growth is sensitive to hypoxia. Additionally, the lack of a difference in relative condition factor between normoxic and hypoxic types suggests the lengthweight relationship may be invariant with respect to hypoxia. Such outcomes could have implications for simulating and predicting the effects of differential exposure to hypoxia on population sustainability for croaker in the northern Gulf of Mexico.

It is important to recognize that while some uncertainty exists in the identification of exposure history, the validated relationships between ambient salinity and dissolved oxygen with otolith $\mathrm{Ba}: \mathrm{Ca}$ and $\mathrm{Mn}: \mathrm{Ca}$ ratios, respectively, facilitate reliable reconstructions of salinity and dissolved oxygen exposures (Mohan et al. 2014, Mohan \& Walther 2016). Moreover, the otolith thresholds set for Ba:Ca $\left(20 \mu \mathrm{mol} \mathrm{mol}^{-1}\right)$ and $\mathrm{Mn}: \mathrm{Ca}\left(100 \mu \mathrm{mol} \mathrm{mol}{ }^{-1}\right)$ were conservative relative to ambient salinity and dissolved oxygen concentrations measured under field and laboratory conditions (Mohan \& Walther 2016).

\section{Exposure diversity}

Our work indicates that croaker interact in complex ways with the dynamic hypoxic zone in the northern Gulf of Mexico as well as both normoxic and estuarine environments. While one-third of croaker sampled in 2014 were exposed to hypoxic conditions in the first year of life, there was substantial variability in the magnitude of hypoxia exposure as indicated by the hypoxia index. Some of this variability is likely due to the dynamic nature of bottomwater hypoxia in the northern Gulf of Mexico. Hypoxia in the northern Gulf of Mexico is often patchy and ephemeral during March through May and most widespread, persistent, and severe from June through August (Rabalais et al. 2001). Inter-annual variability in factors like oceanic currents, riverine discharge, and nutrient loading from the Mississippi River can also result in wide fluctuations in the extent of hypoxia. For example, strong west to east currents in association with drought conditions in 2000 resulted in a hypoxic zone estimated to cover only $4400 \mathrm{~km}^{2}$ (Rabalais et al. 2001), while the hypoxic zone in 2002 was the largest recorded prior to 2017 , 
covering approximately $22000 \mathrm{~km}^{2}$ (Rabalais et al. 2007). Spatial and temporal changes in the hypoxic zone dictate the degree of exposure and subsequent responses of some organisms with limited mobility (Burnett \& Stickle 2001, Wu 2002). However, most organisms (including croaker) are not stationary recorders of changing environments, and the onset of hypoxia may elicit behavioral responses that modulate hypoxia exposure.

Behavioral responses to hypoxia are complex and are likely influenced by species-specific and individual tolerances to low oxygen concentrations and the nature of hypoxia (e.g. episodic or chronic; Bell \& Eggleston 2005). The $34 \%$ of croaker surveyed that experienced hypoxia and survived suggests some individuals of this species are tolerant to hypoxia exposure. Hypoxia avoidance thresholds displayed by late juvenile croaker range as low as 1.0 to $2.7 \mathrm{mg}$ $\mathrm{l}^{-1}$ DO and are noted to vary among years with changing hypoxia severity (Craig 2012). YOY and Age-1 croaker also apparently continue to feed benthically under hypoxic conditions rather than switching to primarily pelagic-based prey sources, suggesting trophic resilience to hypoxia (Mohan \& Walther 2016). This lack of a trophic displacement from benthic food webs may be driven by increased susceptibility of stressed or moribund benthic infaunal prey items to predation as the duration of hypoxia increases (Long \& Seitz 2008). Though our research did not aim to characterize specific behavioral mechanisms underlying variability in hypoxia exposure, it seems probable that excursions into hypoxic areas for feeding during the first year of life may contribute to the prevalence of hypoxia exposure. Even if croaker are tolerant to hypoxia, the majority of individuals sampled in this study did not experience hypoxic conditions. Thus, hypoxia avoidance or increased use of estuarine habitats were also important components of exposure diversity.

Similarity in habitat salinity (Ba:Ca) index values between normoxic and hypoxic type croaker suggest that normoxic type croaker are avoiding hypoxic conditions rather than using habitats of disparate salinities. Laboratory and field studies have documented hypoxia avoidance behaviors in this species (Wannamaker \& Rice 2000, Eby \& Crowder 2002, Campbell \& Rice 2014), as hypoxia exposure may be associated with an increased energetic cost of oxygen regulation that ultimately reduces aerobic scope of activity (Chabot \& Claireaux 2008, Hanks \& Secor 2011). Consequently, growth, consumption rate, and even predator avoidance capabilities may be compromised under hypoxic conditions (McNatt \& Rice
2004, Chabot \& Claireaux 2008, Hanks \& Secor 2011, Roberts et al. 2011). In the Gulf of Mexico, juvenile croaker aggregate on the edge of hypoxic areas and may also utilize deeper offshore waters outside the hypoxic region (Craig \& Crowder 2005). Thus, the mobile nature of this species (Craig \& Crowder 2005) along with proximate drivers of hypoxia avoidance may account for the third of normoxic-type croaker that experience similar habitat salinities as hypoxic fish, but avoid hypoxic conditions.

One-third of the croaker in this study also appeared to utilize estuarine habitats and may not have experienced hypoxic conditions. This is similar to the proportion of YOY and Age-1 croaker utilizing estuarine habitats observed by Mohan \& Walther (2016) of $29 \%$. Although eutrophication is extensive throughout estuaries bordering the Gulf of Mexico (Bricker et al. 1999), estuarine hypoxia may not develop (Mohan \& Walther 2015) or may occur in localized areas (Yakupzack et al. 1977, Montagna \& Froeschke 2009) that are avoidable by croaker (Eby \& Crowder 2002; Campbell \& Rice 2014). Indeed, Campbell \& Rice (2014) observed avoidance of intruding hypoxia by juvenile croaker that occurred over short periods of time (i.e. hours). Putative exposure to estuarine hypoxia may also be confounded by varying levels of dissolved manganese exported by rivers bordering the Gulf of Mexico (Mohan \& Walther 2016). Therefore, while we do not know if estuarine-type croaker in our study were avoiding estuarine hypoxia, they are capable of responding quickly to declines in dissolved oxygen concentrations that may occur in estuaries. It is important to note that combining both a salinity proxy (Ba:Ca) and a hypoxia proxy (Mn:Ca) provided an understanding of exposure history that neither one nor the other could provide alone. Moreover, examinations of potential sublethal effects of hypoxia exposure on growth and condition factor were based on an understanding of hypoxia exposure during the first year of life.

Because waterborne barium is the dominant source of barium incorporated into the otolith (Walther \& Thorrold 2006, Doubleday et al. 2013), and given the estuarine-dependent life history of this species, it is probable that normoxic fish utilized estuarine areas away from freshwater inputs. Changes in Ba:Ca concentrations in estuarine environments are often most pronounced at low to mid salinities (e.g. <15) where increases in $\mathrm{Ba}$ :Ca with decreasing salinity are most prominent (Coffey et al. 1997, Walther \& Nims 2015, Mohan \& Walther 2016). It is possible that juvenile croaker using lower portions of estuaries close to the estuary-ocean interface or far from freshwater inputs 
may not be exposed to Ba:Ca ratios that reflect extensive use of low salinity habitats. In our study, the otolith Ba:Ca threshold of $20 \mu \mathrm{mol} \mathrm{mol}^{-1}$ corresponds to an approximate salinity of 19 . Thus, it is possible that individuals categorized as normoxic did indeed inhabit estuarine environments during their first year of life, but primarily used areas with salinities $>19$. This could explain the unexpectedly low proportions of croaker categorized as explicitly using estuaries and indicates some individuals do utilize habitats with salinities < 19 given substantially elevated otolith Ba:Ca.

Diversity in estuarine habitat use may be represented by variable estuarine ingress and egress timing. Estuarine ingress timing for croaker can vary from 1 to 3 mo after spawning (Hoover et al. 2012, Kupchik \& Shaw 2016). Moreover, Kupchik \& Shaw (2016) found that while the majority of croaker collected hatched between September and October, up to $23 \%$ of hatching occurred between January and February during 1 of the 2 years of study. It is possible that variability in the estuarine index may reflect variable hatch dates and subsequent estuarine ingress timing. Residence time in the estuary also varies greatly for this species. Arnoldi et al. (1974) used a mark-recapture study to determine that residence time of croaker in a Louisiana marsh varied between 1 and 4 mo. Variable estuarine egress timing was also observed by Mohan \& Walther (2016), who identified 'early' and 'late' estuarine emigrants based on differences in muscle isotope $\left(\delta^{13} \mathrm{C}\right.$ and $\left.\delta^{15} \mathrm{~N}\right)$ values and otolith Ba:Ca. These authors observed greater isotopic niche areas in estuarine individuals than offshore individuals (reflecting greater contribution of terrestrially derived organic carbon) but different Ba:Ca index values between estuarine groups indicating differential timing of movement into higher salinity (lower Ba:Ca) environments.

Consistent differences in $\mathrm{Ba}: \mathrm{Ca}$ endmembers among river systems draining into estuaries in the region may also contribute to variable exposure histories, and such differences may be large (Walther \& Nims 2015). Mixing curves developed for $\mathrm{Ba}: \mathrm{Ca}$ in the Mississippi River (salinity coverage $\sim 1$ to 37 ; Cai 2003, Shim et al. 2012, Mohan \& Walther 2016) and the Calcasieu river in Louisiana (He \& Xu 2016) suggest low salinity (i.e. $<5$ ) Ba:Ca endmembers are substantially higher in the Calcasieu River $(\geq 2$-fold greater than the Mississippi River at salinity of 5). Combined with seasonal up-estuary movements by juvenile croaker (such as seen in the Cape Fear River, NC; Ross 2003), and a tendency for YOY to remain in these areas until fall egress (Able \& Fahay
2010), inter-estuarine differences in otolith $\mathrm{Ba}: \mathrm{Ca}$ are likely. This study chose a conservative Ba:Ca threshold indicating estuarine residence to account for potential inter-estuary differences in elemental value, and future work that incorporates estuary-specific estuarine residence thresholds could further refine the geographical patterns of residence in particular systems.

\section{Biometric comparisons}

Growth, but not relative condition factor appeared responsive to exposure to hypoxic conditions in YOY croaker. YOY croaker classified as exposed to hypoxia were shorter in total length and smaller in mass than YOY croaker classified as normoxic, but not shorter or smaller than those classified as estuarine. This suggests that hypoxia exposure may result in growth suppression, although not relative to individuals using estuarine habitats. In laboratory experiments lasting 4 and $10 \mathrm{wk}$, YOY croaker exposed to hypoxia (1.7 $\left.\mathrm{mg} \mathrm{l}^{-1} \mathrm{DO}\right)$ showed reductions in condition factor relative to those exposed to normoxic conditions (Mohan et al. (2014). It is also possible that individual variability in growth (Barger 1985, Barbieri et al. 1994) independent of hypoxia exposure could result in differential susceptibility to hypoxia. For example, Breitburg (1992) demonstrated that the ability of a fish to avoid hypoxia may differ ontogenetically. Breitburg (1992) inferred that smaller individuals of the naked goby Gobiosoma bosc in Chesapeake Bay were more susceptible to hypoxia exposure given lower mobility (relative to large individuals) and, thus, would need to anticipate hypoxia and initiate escape behaviors earlier than larger, more mobile individuals. Considering that optimal swimming speed is positively related to mass, and that the cost of transport at optimum swimming speed decreases with fish size (Wootton 1998), larger croaker may be more efficient at avoiding hypoxic waters than smaller conspecifics.

The lack of a difference in relative condition factors between normoxic and hypoxic croaker may represent both the transient nature of condition, and an underlying mechanism for surviving hypoxic conditions at the expense of reproductive output. Under hypoxic laboratory conditions, reductions in condition factors of YOY croaker were observed after 4, 10, (Mohan et al. 2014), 15, and 20 wk (Rahman \& Thomas 2011) of constant exposure. However, after 5 wk of recovery under normoxic conditions, Rahman \& Thomas (2011) observed no differences between 
control YOY croaker and those previously held in hypoxia, suggesting any potential effects on condition factor may be transient. Croaker in the current study were collected at the end of October and beginning of November, which is after the timeframe hypoxia is typically observed in the northern Gulf of Mexico (Rabalais et al. 2001). Indeed, only a single station of the 22 sampled displayed bottom water DO levels close to $2.0 \mathrm{mg} \mathrm{l}^{-1}$ (Table S1). If condition factor was affected by hypoxia, differences may have been undetectable by the time croaker were sampled. Alternatively, Tuckey \& Fabrizio (2016) observed slight, but non-significant increases in relative condition of croaker when comparing fish caught before and during hypoxia in the Chesapeake Bay estuary. This outcome may reflect a shift in energy partitioning away from reproductive output to maintenance of somatic condition in order to survive under more costly anaerobic metabolism (Thomas \& Rahman 2012, Tuckey \& Fabrizio 2016). Therefore, condition factor may be maintained under hypoxia at the expense of reproductive integrity (Thomas \& Rahman 2009).

Lower size (total length and mass) but not condition factors observed in estuarine croaker compared to normoxic croakers may be associated with a tradeoff between growth and lipid energy stores required to undertake a migration to offshore breeding grounds. The high estuarine index value that characterizes this group implies increased exposure to upper estuarine environments with salinities < 19 that may be far from open ocean. Indeed, ambient $\mathrm{Ba}$ :Ca measured in estuaries along the Texas coast was highest at sites furthest away from the open ocean and with the lowest salinities (20 to 25; Mohan \& Walther 2015). Increased subdermal lipid contents of juvenile croaker prior to the anticipated timing of egress from Chesapeake Bay suggest an energetic cost of this migration (Schloesser \& Fabrizio 2016). The efficacy of some condition indices to predict lipid content and energy stores in croaker was also improved with the inclusion of fish length, indicating a potential balance between growth and lipid storage (Schloesser \& Fabrizio 2017). A similar tradeoff may have occurred in estuarine-exposed croaker in this study, whereby estuarine individuals trade somatic growth for increased energy stores required to undertake a more extensive migration to offshore breeding grounds. Lower salinities in upper estuarine areas may facilitate this process, as evidenced by small postlarval and early juvenile croaker gaining more mass under low salinity (5) laboratory exposures than in higher salinity (20) exposures, suggest- ing an increased cost of osmoregulation relative to size (Peterson et al. 1999).

It is also possible that ontogenetic salinity associations and density dependent limitations on space and food in estuaries may be leading to reduced growth in juvenile croaker. Upper estuary low-salinity areas were found to reduce mortality risk to juvenile croaker (Ross 2003) but could come at the cost of reduced growth under crowded conditions. Searcy et al. (2007) hypothesized that food depletion in the Newport River estuary, North Carolina, driven by both croaker density and a physical barrier to movement (i.e. a shallow sill) resulted in reduced growth. Hypoxia-induced habitat compression (Eby \& Crowder 2002, Campbell \& Rice 2014) that causes increased competition for space and a reduction in, or isolation from, food resources (Eby et al. 2005, Casini et al. 2016) may also suppress growth. Because croaker in our study were captured offshore, there is uncertainty with regard to nursery estuaries and whether density dependent mechanisms may have acted to suppress growth. Additionally, while some croaker in estuarine clusters E1 and E2 display simultaneous Ba:Ca and $\mathrm{Mn}$ :Ca otolith signals above the respective thresholds (Fig. 4), which may indicate estuarine hypoxic conditions (J. Mohan pers. comm.), the link between simultaneously elevated $\mathrm{Ba}: \mathrm{Ca}$ and $\mathrm{Mn}: \mathrm{Ca}$ and estuarine hypoxia has yet to be validated.

\section{Management implications}

Chronic seasonal hypoxia is of conservation concern because it causes displacement (Craig 2012), stress, and increased mortality rates as dissolved oxygen concentrations approach and decline below $2.0 \mathrm{mg} \mathrm{l}^{-1}$ (Breitburg 2002, Levin et al. 2009). A recent study by Casini et al. (2016) documented declines in condition factor (11 to $22 \%$ ) of cod in the Baltic Sea associated with indirect effects (e.g. crowding and reduced prey availability) of a growing hypoxic zone. In adult YOY croaker, exposure to hypoxia is also known to result in multiple deleterious reproductive outcomes (Thomas \& Rahman 2010, 2012, Thomas et al. 2015). The problematic consequences of hypoxia exposure for croaker may have direct implications for the management of this species in the Gulf of Mexico. For this recreationally and commercially important species (Diamond et al. 1999), efforts to understand how seasonal hypoxia affects population sustainability have been undertaken by integrating hypoxia forecasts with life history characteristics and known reproductive impair- 
ments (Rose et al. 2009). An important data gap in these efforts, however, is an empirically based estimate of the proportion of croaker exposed to hypoxia (Rose et al. 2009).

The estimates of the proportion of croaker exposed to hypoxia in this study may help increase the predictive power of simulation models that seek to elucidate population dynamics in association with changing hypoxic regimes. Recent model simulations of such effects have relied on arbitrary estimates of proportional hypoxia exposure levels (e.g. $10 \%, 25 \%$, or $50 \%$ exposure; Rose et al. 2009) or have applied mechanisms such as increasing density-dependent mortality with increasing hypoxia volume as a function of precipitation (Diamond et al. 2013). A caveat to the estimate of direct hypoxia exposure in this study $(34 \%)$ is that it only quantifies those individuals that survived exposure to hypoxia and may thus be an underestimate. However, because survivors would be the individuals potentially reproducing, an underestimate in this respect is still an important value for population simulations. Whether or not surviving hypoxic croaker then experience differential mortality over subsequent years relative to normoxic or estuarine individuals remains to be seen, but may also be important to predictive scenarios seeking to make inference between hypoxia exposure and population level outcomes.

The identification of individuals exposed to hypoxia may also facilitate improvements in modeled sublethal effects that are important for assessing population productivity. YOY croaker exposed to hypoxia in this study were significantly shorter and weighed less than those that had not experienced hypoxia. Because fecundity is closely tied to total length and mass (Morse 1980), smaller individuals would be expected to produce fewer eggs than larger individuals, regardless of hypoxia exposure. Simulations assuming reproductive impairments based on age-fecundity relationships (and the physiological impacts described above) may overestimate reproductive consequences if smaller individuals experience hypoxia at a greater rate than larger individuals. However, seasonal variability in growth rates (Kupchik \& Shaw 2016) may modulate any relationship between smaller body size and increased prevalence of hypoxia exposure. In the context that simulated population abundance of croaker responded in a non-multiplicative fashion based on conditions included in a simulation model (e.g. fecundity alone; Rose et al. 2009), the effects or importance of integrating size-based exposure into such models remains to be seen.

\section{Conclusions}

The quantification of proportional habitat use within normoxic, hypoxic, and estuarine areas was possible using a combined otolith salinity (Ba:Ca) and hypoxia (Mn:Ca) proxy approach. This method in association with measurements of body size and condition indicates that while this species is tolerant to hypoxia, growth suppression relative to normoxictype fish, but similar to that observed in estuarinetype fish, may be consequential for population sustainability. Quantification of hypoxia exposure also helps fill a knowledge gap of exposure proportions useful for modeling simulated changes in population abundance in the face of hypoxia. Moreover, this work lays the foundation for examinations of differential survival based on exposure to hypoxia as another mechanism affecting population sustainability of croaker in the northern Gulf of Mexico.

Acknowledgements. Funding for this project was provided by the National Science Foundation (NSF-OCE-1633020). We thank A. Debose and the crew of the NOAA ship RV 'Oregon II' for their assistance collecting croaker in the Gulf of Mexico. We also thank N. Miller for his technical expertise and support in collecting and analyzing otolith chemical data, and J. Mohan for his advice on data analysis and interpretation. Many people also assisted in the laboratory including C. Guerrero, A. Guerrero, S. Mohan, M. Phillips, Z. Russell, T. Steube, and L. Torrance. Comments from K. Limburg, J. Mohan, and M. Samson and 3 anonymous reviewers greatly improved prior drafts of the manuscript.

\section{LITERATURE CITED}

Able KW, Fahay MP (2010) Ecology of estuarine fishes: temperate waters of the Western North Atlantic. Johns Hopkins University Press, Baltimore, MD

Arnoldi DC, Herke WH, Clairian EJ Jr (1974) Estimate of growth rate and length of stay in a marsh nursery of juvenile Atlantic croaker, Micropogon undulatus (Linnaeus), 'sandblasted' with fluorescent pigments. Proc Gulf Caribb Fish Inst 26:158-172

Barbieri LR, Chittenden ME, Lowerrebarbieri SK (1994) Maturity, spawning, and ovarian cycle of Atlantic croaker, Micropogonias undulatus, in the Chesapeake Bay and adjacent coastal waters. Fish Bull 92:671-685

* Barger LE (1985) Age and growth of Atlantic croakers in the northern Gulf of Mexico, based on otolith sections. Trans Am Fish Soc 114:847-850

Bell GW, Eggleston DB (2005) Species-specific avoidance responses by blue crabs and fish to chronic and episodic hypoxia. Mar Biol 146:761-770

Breitburg DL (1992) Episodic hypoxia in Chesapeake Bay: interacting effects of recruitment, behavior, and physical disturbance. Ecol Monogr 62:525-546

Breitburg D (2002) Effects of hypoxia, and the balance between hypoxia and enrichment, on coastal fishes and 
fisheries. Estuaries 25:767-781

Breitburg DL, Hondorp DW, Davias LA, Diaz RJ (2009) Hypoxia, nitrogen, and fisheries: integrating effects across local and global landscapes. Annu Rev Mar Sci 1:329-349

Bricker SB, Clement CG, Pirhalla DE, Orlando SP, Farrow DRG (1999) National estuarine eutrophication assessment: effects of nutrient enrichment in the nation's estuaries. NOAA, National Ocean Service, Special Projects Office and the National Centers for Coastal Ocean Science, Silver Spring, MD

Burnett LE, Stickle WB (2001) Physiological responses to hypoxia. In: Rabalais NN, Turner RE (eds) Coastal hypoxia: consequences for living resources and ecosystems. American Geophysical Union, Washington, DC

* Cai WJ (2003) Riverine inorganic carbon flux and rate of biological uptake in the Mississippi River plume. Geophys Res Lett 30:1032

* Campana SE (1999) Chemistry and composition of fish otoliths: pathways, mechanisms and applications. Mar Ecol Prog Ser 188:263-297

Campana SE, Thorrold SR (2001) Otoliths, increments, and elements: keys to a comprehensive understanding of fish populations? Can J Fish Aquat Sci 58:30-38

Campbell LA, Rice JA (2014) Effects of hypoxia-induced habitat compression on growth of juvenile fish in the Neuse River Estuary, North Carolina, USA. Mar Ecol Prog Ser 497:199-213

Casini M, Käll F, Hansson M, Plikshs M and others (2016) Hypoxic areas, density-dependence and food limitation drive the body condition of a heavily exploited marine fish predator. R Soc Open Sci 3:160416

Chabot D, Claireaux G (2008) Environmental hypoxia as a metabolic constraint on fish: the case of Atlantic cod, Gadus morhua. Mar Pollut Bull 57:287-294

Chabot D, Dutil JD (1999) Reduced growth of Atlantic cod in non-lethal hypoxic conditions. J Fish Biol 55:472-491

* Coffey M, Dehairs F, Collette O, Luther G, Church T, Jickells $\mathrm{T}$ (1997) The behaviour of dissolved barium in estuaries. Estuar Coast Shelf Sci 45:113-121

Craig JK (2012) Aggregation on the edge: effects of hypoxia avoidance on the spatial distribution of brown shrimp and demersal fishes in the northern Gulf of Mexico. Mar Ecol Prog Ser 445:75-95

Craig JK, Crowder LB (2005) Hypoxia-induced habitat shifts and energetic consequences in Atlantic croaker and brown shrimp on the Gulf of Mexico shelf. Mar Ecol Prog Ser 294:79-94

* Diamond SL, Crowder LB, Cowell LG (1999) Catch and bycatch: the qualitative effects of fisheries on population vital rates of Atlantic croaker. Trans Am Fish Soc 128: 1085-1105

Diamond SL, Murphy CA, Rose KA (2013) Simulating the effects of global climate change on Atlantic croaker population dynamics in the mid-Atlantic Region. Ecol Modell 264:98-114

* Diaz RJ, Rosenberg R (2008) Spreading dead zones and consequences for marine ecosystems. Science 321:926-929

* Doubleday Z, Izzo C, Woodcock S, Gillanders B (2013) Relative contribution of water and diet to otolith chemistry in freshwater fish. Aquat Biol 18:271-280

Eby LA, Crowder LB (2002) Hypoxia-based habitat compression in the Neuse River Estuary: context-dependent shifts in behavioral avoidance thresholds. Can J Fish Aquat Sci 59:952-965
Eby LA, Crowder LB, McClellan CM, Peterson CH, Powers MJ (2005) Habitat degredation from intermittent hypoxia: impacts on demersal fishes. Mar Ecol Prog Ser 291: 249-261

FElsdon TS, Gillanders BM (2005) Alternative life-history patterns of estuarine fish: barium in otoliths elucidates freshwater residency. Can J Fish Aquat Sci 62:1143-1152

GSMFC (2017) Environmental and biological atlas of the Gulf of Mexico 2015. Gulf States Marine Fisheries Commission, Report 263

*Hamidi SA, Bravo HR, Klump JV, Waples JT (2015) The role of circulation and heat fluxes in the formation of stratification leading to hypoxia in Green Bay, Lake Michigan. J Gt Lakes Res 41:1024-1036

Hanks DM, Secor DH (2011) Bioenergetic responses of Chesapeake Bay white perch (Morone americana) to nursery conditions of temperature, dissolved oxygen, and salinity. Mar Biol 158:805-815

*Haven DS (1957) Distribution, growth, and availability of juvenile croaker, Micropogon undulatus, in Virginia. Ecology 38:88-97

$\mathrm{He}$ S, Xu Y (2016) Spatiotemporal distributions of Sr and Ba along an estuarine river with a large salinity gradient to the Gulf of Mexico. Water 8:323

*Hecky RE, Bugenyi FWB, Ochumba P, Talling JF, Mugidde R, Gophen M, Kaufman L (1994) Deoxygenation of the deep water of Lake Victoria, East Africa. Limnol Oceanogr 39: $1476-1481$

*Hernandez FJ, Powers SP, Graham WM (2010) Detailed examination of ichthyoplankton seasonality from a highresolution time series in the northern Gulf of Mexico during 2004-2006. Trans Am Fish Soc 139:1511-1525

Holm S (1979) A simple sequentially rejective multiple test procedure. Scand J Stat 6:65-70

* Hoover RR, Jones CM, Grosch CE (2012) Estuarine ingress timing as revealed by spectral analysis of otolith life history scans. Can J Fish Aquat Sci 69:1266-1277

Kupchik MJ, Shaw RF (2016) Age, growth, and recruitment of larval and early juvenile Atlantic croaker (Micropogonias undulatus), determined from analysis of otolith microstructure. Fish Bull 114:18-33

K Laslett RE (1995) Concentrations of dissolved and suspended particulate $\mathrm{Cd}, \mathrm{Cu}, \mathrm{Mn}, \mathrm{Ni}, \mathrm{Pb}$ and $\mathrm{Zn}$ in surface waters around the coasts of England and Wales and in adjacent seas. Estuar Coast Shelf Sci 40:67-85

* Le Cren ED (1951) The length-weight relationship and seasonal cycle in gonad weight and condition in the perch (Perca fluviatilis). J Anim Ecol 20:201-219

KLevin LA, Ekau W, Gooday AJ, Jorissen F and others (2009) Effects of natural and human-induced hypoxia on coastal benthos. Biogeosciences 6:2063-2098

Lewis BL, Luther GW (2000) Processes controlling the distribution and cycling of manganese in the oxygen minimum zone of the Arabian Sea. Deep Sea Res II 47:1541-1561

Limburg KE, Olson C, Walther Y, Dale D, Slomp CP, Hoie H (2011) Tracking Baltic hypoxia and cod migration over millennia with natural tags. Proc Natl Acad Sci USA 108: E177-E182

* Limburg KE, Walther BD, Lu ZL, Jackman G and others (2015) In search of the dead zone: use of otoliths for tracking fish exposure to hypoxia. J Mar Syst 141:167-178

* Long WC, Seitz RD (2008) Trophic interactions under stress: hypoxia enhances foraging in an estuarine food web. Mar Ecol Prog Ser 362:59-68 
McNatt RA, Rice JA (2004) Hypoxia-induced growth rate reduction in two juvenile estuary-dependent fishes. J Exp Mar Biol Ecol 311:147-156

Miglarese JV, Mcmillan CW, Shealy MH (1982) Seasonal abundance of Atlantic croaker (Micropogonias undulatus) in relation to bottom salinity and temperature in South Carolina estuaries. Estuaries 5:216-223

Mohan JA, Walther BD (2015) Spatiotemporal variation of trace elements and stable isotopes in subtropical estuaries: II. Regional, local, and seasonal salinity-element relationships. Estuar Coast 38:769-781

Mohan J, Walther B (2016) Out of breath and hungry: natural tags reveal trophic resilience of Atlantic croaker to hypoxia exposure. Mar Ecol Prog Ser 560:207-221

* Mohan J, Rahman M, Thomas P, Walther B (2014) Influence of constant and periodic experimental hypoxic stress on Atlantic croaker otolith chemistry. Aquat Biol 20:1-11

Montagna PA, Froeschke J (2009) Long-term biological effects of coastal hypoxia in Corpus Christi Bay, Texas, USA. J Exp Mar Biol Ecol 381:S21-S30

Morse WW (1980) Maturity, spawning, and fecundity of Atlantic croaker, Micropogonias undulatus, occurring north of Cape Hatteras, North Carolina. Fish Bull 78: 190-195

NMFS (2015a) NOAA/NMFS Office of Science \& Technology. Commercial Fisheries Statistics. www.st.nmfs.noaa.gov/ commercial-fisheries/index (accessed 20 Oct 2015)

NMFS (2015b) NOAA/NMFS Office of Science \& Technology. Marine Recreational Information Program. www.st. nmfs.noaa.gov/recreational-fisheries/index (accessed 20 Oct 2015)

* Peterson MS, Comyns BH, Rakocinski CF, Fulling GL (1999) Does salinity affect somatic growth in early juvenile Atlantic croaker, Micropogonias undulatus (L.)? J Exp Mar Biol Ecol 238:199-207

Rabalais NN, Turner RE, Wiseman WJ (2001) Hypoxia in the Gulf of Mexico. J Environ Qual 30:320-329

Rabalais NN, Turner RE, Wiseman WJ (2002) Gulf of Mexico hypoxia, A.K.A. 'the dead zone'. Annu Rev Ecol Syst 33: 235-263

Rabalais NN, Turner RE, Sen Gupta BK, Boesch DF, Chapman P, Murrell MC (2007) Hypoxia in the northern Gulf of Mexico: Does the science support the plan to reduce, mitigate, and control hypoxia? Estuaries Coasts 30:753-772

* Rabalais NN, Diaz RJ, Levin LA, Turner RE, Gilbert D, Zhang J (2010) Dynamics and distribution of natural and human-caused hypoxia. Biogeosciences 7:585-619

Rabalais NN, Cai WJ, Carstensen J, Conley DJ and others (2014) Eutrophication-driven deoxygenation in the coastal ocean. Oceanography (Wash DC) 27:172-183

Rahman MS, Thomas P (2007) Molecular cloning, characterization and expression of two hypoxia-inducible factor alpha subunits, HIF-1 alpha and HIF-2 alpha, in a hypoxia-tolerant marine teleost, Atlantic croaker (Micropogonias undulatus). Gene 396:273-282

* Rahman MS, Thomas P (2011) Characterization of three IGFBP mRNAs in Atlantic croaker and their regulation during hypoxic stress: potential mechanisms of their upregulation by hypoxia. Am J Physiol Endocrinol Metab 301:E637-E648

Roberts JJ, Brandt SB, Fanslow D, Ludsin SA, Pothoven SA, Scavia D, Hook TO (2011) Effects of hypoxia on consumption, growth, and RNA:DNA ratios of young yellow perch. Trans Am Fish Soc 140:1574-1586
Rose KA, Adamack AT, Murphy CA, Sable SE and others (2009) Does hypoxia have population-level effects on coastal fish? Musings from the virtual world. J Exp Mar Biol Ecol 381:S188-S203

Ross SW (2003) The relative value of different estuarine nursery areas in North Carolina for transient juvenile marine fishes. Fish Bull 101:384-404

* Scavia D, Allan JD, Arend KK, Bartell S and others (2014) Assessing and addressing the re-eutrophication of Lake Erie: central basin hypoxia. J Gt Lakes Res 40:226-246

Schloesser RW, Fabrizio MC (2016) Temporal dynamics of condition for estuarine fishes in their nursery habitats. Mar Ecol Prog Ser 557:207-219

* Schloesser RW, Fabrizio MC (2017) Condition indices as surrogates of energy density and lipid content in juveniles of three fish species. Trans Am Fish Soc 146:1058-1069

* Searcy SP, Eggleston DB, Hare JA (2007) Is growth a reliable indicator of habitat quality and essential fish habitat for a juvenile estuarine fish? Can J Fish Aquat Sci 64:681-691

Southeast Data, Assessment \& Review (SEDAR) (2017) Southeast data, assessment, and review. SEDAR. http://sedar web.org/docs/wsupp/S27_RD_05_SEAMAP\%20TRAWL\% 20PROTOCOL.pdf (accessed 24 Oct 2017)

Shim MJ, Swarzenski PW, Shiller AM (2012) Dissolved and colloidal trace elements in the Mississippi River delta outflow after Hurricanes Katrina and Rita. Cont Shelf Res 42:1-9

Sinclair DJ, Kinsley LPJ, McCulloch MT (1998) High resolution analysis of trace elements in corals by laser ablation ICP-MS. Geochim Cosmochim Acta 62:1889-1901

Sokal RR, Rohlf FJ (1995) Single-classification analysis of variance. In: Sokal RR, Rohlf FJ (eds) Biometry: the principles and practice of statistics in biological research. WH Freeman and Company, New York, NY

* Statham PJ, Connelly DP, German CR, Brand T and others (2005) Spatially complex distribution of dissolved manganese in a fjord as revealed by high-resolution in situ sensing using the autonomous underwater vehicle autosub. Environ Sci Technol 39:9440-9445

* Thomas P, Rahman MS (2009) Biomarkers of hypoxia exposure and reproductive function in Atlantic croaker: a review with some preliminary findings from the northern Gulf of Mexico hypoxic zone. J Exp Mar Biol Ecol 381: S38-S50

* Thomas P, Rahman MS (2010) Region-wide impairment of Atlantic croaker testicular development and sperm production in the northern Gulf of Mexico hypoxic dead zone. Mar Environ Res 69:S59-S62

*Thomas P, Rahman MS (2012) Extensive reproductive disruption, ovarian masculinization and aromatase suppression in Atlantic croaker in the northern Gulf of Mexico hypoxic zone. Proc R Soc B 279:28-38

Thomas P, Rahman MS, Picha ME, Tan WX (2015) Impaired gamete production and viability in Atlantic croaker collected throughout the $20000 \mathrm{~km}^{2}$ hypoxic region in the northern Gulf of Mexico. Mar Pollut Bull 101:182-192

* Thorrold SR, Shuttleworth S (2000) In situ analysis of trace elements and isotope ratios in fish otoliths using laser ablation sector field inductively coupled plasma mass spectrometry. Can J Fish Aquat Sci 57:1232-1242

Tuckey TD, Fabrizio MC (2016) Variability in fish tissue proximate composition is consistent with indirect effects of hypoxia in Chesapeake Bay tributaries. Mar Coast Fish 8:1-15 
Turner RE, Rabalais NN (1994) Coastal eutrophication near the Mississippi river delta. Nature 368:619-621

Walther B, Nims M (2015) Spatiotemporal variation of trace elements and stable isotopes in subtropical estuaries: I. Freshwater endmembers and mixing curves. Estuaries Coasts 38:754-768

Walther BD, Thorrold SR (2006) Water, not food, contributes the majority of strontium and barium deposited in the otoliths of a marine fish. Mar Ecol Prog Ser 311: 125-130

Wannamaker CM, Rice JA (2000) Effects of hypoxia on movements and behavior of selected estuarine organisms from the southeastern United States. J Exp Mar Biol Ecol 249:145-163

Ward J (1963) Heirarchical grouping to optimize an objec-

Editorial responsibility: Stylianos Somarakis,

Heraklion, Greece tive function. J Am Stat Assoc 58:236-244

White ML, Chittenden ME Jr (1977) Age determination, reproduction, and population dynamics of the Atlantic croaker, Micropogonias undulatus. Fish Bull 75:109-123

Wootton RJ (1998) Ecology of teleost fishes. Kluwer Academic Publishers, Dordrecht

*Wu RSS (2002) Hypoxia: from molecular responses to ecosystem responses. Mar Pollut Bull 45:35-45

* Wu RSS, Zhou BS, Randall DJ, Woo NYS, Lam PKS (2003) Aquatic hypoxia is an endocrine disruptor and impairs fish reproduction. Environ Sci Technol 37:1137-1141

Y Yakupzack PM, Herke WH, Perry WG (1977) Emigration of juvenile Atlantic croakers, Micropogon undulatus, from a semi-impounded march in southwestern Louisiana. Trans Am Fish Soc 106:538-544

Submitted: June 2, 2017; Accepted: December 22, 2017 Proofs received from author(s): February 9, 2018 